\title{
Antidepressant-like effect of Hoodia gordonii in a forced swimming test in mice: evidence for involvement of the monoaminergic system
}

\author{
M.C.O. Citó, M.I.G. Silva, L.K.X. Santos, M.L. Fernandes, F.H.C. Melo, J.A.C. Aguiar, I.S. Lopes, \\ P.B. Sousa, S.M.M. Vasconcelos, D.S. Macêdo and F.C.F. Sousa \\ Laboratório de Neurofarmacologia, Departamento de Fisiologia e Farmacologia, \\ Universidade Federal do Ceará, Fortaleza, CE, Brasil
}

\begin{abstract}
Hoodia gordonii is a plant species used traditionally in southern Africa to suppress appetite. Recently, it has been associated with a significant increase in blood pressure and pulse rate in women, suggesting sympathomimetic activity. The present study investigated the possible antidepressant-like effects of acute and repeated (15 days) administration of $H$. gordonii extract (25 and $50 \mathrm{mg} / \mathrm{kg}$, po) to mice exposed to a forced swimming test (FST). Neurochemical analysis of brain monoamines was also carried out to determine the involvement of the monoaminergic system on these effects. Acute administration of $H$. gordonii decreased the immobility of mice in the FST without accompanying changes in general activity in the open-field test during acute treatment, suggesting an antidepressant-like effect. The anti-immobility effect of $H$. gordonii was prevented by pretreatment of mice with PCPA [an inhibitor of serotonin (5-HT) synthesis], NAN-190 (a 5-HT 1 A antagonist), ritanserin (a $5-\mathrm{HT}_{2 \mathrm{~A} / 2 \mathrm{C}}$ antagonist), ondansetron (a 5-HT3 $\mathrm{A}$ antagonist), prazosin (an $\alpha 1$-adrenoceptor antagonist), $\mathrm{SCH} 23390$ (a $\mathrm{D}_{1}$ receptor antagonist), yohimbine (an $\alpha 2$-adrenoceptor antagonist), and sulpiride $\left(a D_{2}\right.$ receptor antagonist). A significant increase in 5-HT levels in the striatum was detected after acute administration, while 5-HT, norepinephrine and dopamine were significantly elevated after chronic treatment. Results indicated that $H$. gordonii possesses antidepressant-like activity in the FST by altering the dopaminergic, serotonergic, and noradrenergic systems.
\end{abstract}

Key words: Hoodia gordonii; Antidepressant action; Monoaminergic system; Forced swimming test

\section{Introduction}

Depression is one of the most prevalent chronic neuropsychiatric disorders that affects up to $20 \%$ of the population around the globe (1). Although several classes of antidepressants are currently being used in the treatment of this disorder, because of limited efficacy and undesirable adverse effects of treatments, chronic and recurrent depression is still present at high rates. Accordingly, there is growing interest in the development of efficient and safe drugs as alternative therapeutics for the management of this mental illness (2).

Traditional medicine from around the world relies on the use of a wide variety of medicinal plants. In recent years, an increasing number of studies have demonstrated numerous plant species exhibiting a variety of promising pharmacological properties, including actions on the central nervous system (CNS), such as anxiolytic and antidepressive effects (3-5).

Hoodia gordonii (Masson) Sweet ex Decne is a cactus-like succulent species from the Apocycnacaea family used traditionally among the San tribe of southern Africa to suppress appetite when away on long hunting trips (6). This traditional use was further validated in initial exploratory research when an oxypregnane glycoside (P57) was proposed as the active compound related to weight loss induced by administration of $H$. gordonii to female rats (7). From these studies, $H$. gordonii has gained increasing interest as a natural appetite suppressant in weight management, and products containing the species have been marketed in several countries around the world. However, because of the absence of scientific evidence for its efficacy and safety, the sale of $H$. gordonii was prohibited in Brazil by the National Health Surveillance Agency in February 2007.

In a recent study, the administration of a purified extract of $H$. gordonii was associated with a significant increase in the blood pressure and pulse rate of women, suggesting possible sympathomimetic activity (8).

Correspondence: F.C.F. Sousa: <cleaflorenco@yahoo.com.br>

Received July 1, 2014. Accepted September 2, 2014. First published online November 7, 2014. 
Although the effects of this plant on food intake are the focus in the literature, some sympathomimetic activity related to mood disorders could also be detected from $H$. gordonii. However, this hypothesis has still not been explored. Taking this into consideration, the present study investigated a possible antidepressant-like action of acute and chronic doses of $H$. gordonii extract administered to mice and tested in the forced swimming test (FST) (9), one of the most common animal models used for screening antidepressant drugs.

The FST is also an important tool for studying the neurobiological mechanisms involved in antidepressant responses. In fact, numerous studies have shown that the modulation of the serotonergic, noradrenergic, and dopaminergic systems in this animal model underlies the behavioral effects of several antidepressants $(10,11)$. Thus, bearing in mind the monoaminergic theory of depression, the involvement of serotonergic, noradrenergic, and dopaminergic systems on the effects of $H$. gordonii in the FST was investigated. Furthermore, with the aim of corroborating the results from these studies, we also conducted a neurochemical analysis of brain monoamines in the animals, using high-performance liquid chromatography (HPLC).

\section{Material and Methods}

\section{Animals}

Male Swiss mice (25-30 g) maintained on a 12:12-h light-dark cycle were used in this study. All experiments were carried out at an ambient temperature of $24 \pm 2{ }^{\circ} \mathrm{C}$ with access to food and water ad libitum. Animals were treated in accordance with current law and the National Institutes of Health Guide for the Care and Use of Laboratory Animals. The study was performed with the consent of and under surveillance by the Committee of Ethics in Animal Research (protocol \#05/12) of the Departamento de Fisiologia e Farmacologia, Universidade Federal do Ceará, Fortaleza, CE, Brazil.

\section{Drugs}

In this study, a commercial dry purified extract of $H$. gordonii was used, legally imported from Naturalmedis (UK). This product is manufactured in accordance with the requirements of the Medicines and Healthcare Products Regulatory Agency in the United Kingdom. The active ingredient content (P57) is guaranteed through regular analyses performed by the company's Laboratory for Quality Control. Also, the material was shown to be free of microbiological contamination and was at a dilution of $20: 1$. The purchase of the substance was made for research purposes. For the use of the drug in our experiments, $H$. gordonii was emulsified in $0.3 \%$ Tween 20 (Sigma, USA) and diluted in distilled water. The extract was administered orally to mice, at doses of 25 and $50 \mathrm{mg} / \mathrm{kg}$ in a single dose or for 15 consecutive days.
The additional drugs used is this study were: $10 \mathrm{mg} / \mathrm{kg}$ imipramine (IMI; Geisy, Brazil), $1 \mathrm{mg} / \mathrm{kg}$ prazosin (PZS; Sigma), $1 \mathrm{mg} / \mathrm{kg}$ yohimbine (YOHI; Sigma), $0.05 \mathrm{mg} / \mathrm{kg}$ $\mathrm{SCH} 23390$ (Sigma), 50 mg/kg sulpiride (Sigma), $100 \mathrm{mg} /$ $\mathrm{kg}$-chlorophenylalanine methyl ester (PCPA; Sigma), $0.5 \mathrm{mg} / \mathrm{kg}$ NAN-190 \{1-(2-methoxyphenyl)-4-[4-(2-phthalimido)butyl]piperazine, Sigma $\}, 1 \mathrm{mg} / \mathrm{kg}$ ondansetron (Sigma), $1 \mathrm{mg} / \mathrm{kg}$ ritanserin (Sigma), and $35 \mathrm{mg} / \mathrm{kg}$ fluoxetine (FLU; Sigma). All drugs were diluted in distilled water and administered by the intraperitoneal (ip) route.

\section{FST}

To investigate the effects of the drug in the FST, different groups of mice received 25 and $50 \mathrm{mg} / \mathrm{kg}$ (po) $H$. gordonii or vehicle (po) acutely for 15 consecutive days. Subsequently, 60 min after the last administration, animals were tested in the FST. IMI $(10 \mathrm{mg} / \mathrm{kg}$, ip) was used as the positive control.

The test was conducted using the method of Porsolt et al. (9) with minor modifications. This model is a wellknown screening tool for potential antidepressant drugs. Mice were placed inside a $25-\mathrm{cm}$ glass cylinder $(14 \mathrm{~cm}$ diameter) containing $20 \mathrm{~cm}$ of water maintained at $24 \pm 2^{\circ} \mathrm{C}$ and were forced to swim for $6 \mathrm{~min}$ : $2 \mathrm{~min}$ to adapt to the environment and $4 \mathrm{~min}$ to register immobility time $(12,13)$. Their immobility time was recorded. A mouse was considered immobile when it remained floating in the water, without struggling, making only very slight movements necessary to keep its head above water. Drugs with antidepressant activity reduce that parameter (immobility time), while depressant drugs exert the opposite effect.

Because $H$. gordonii decreased the immobility of mice in the FST, the present model was also used to determine the possible involvement of the monoaminergic system on this action. Thus, to assess the possible contribution of the serotonergic system, mice were pretreated with $100 \mathrm{mg} / \mathrm{kg}$, ip, PCPA, an inhibitor of serotonin (5-HT) synthesis, or vehicle, once a day, for 4 consecutive days. Then, $24 \mathrm{~h}$ after the last PCPA or saline injection, animals were treated with $50 \mathrm{mg} / \mathrm{kg}, p o, H$. gordonii or vehicle, and were tested in the FST $1 \mathrm{~h}$ later. Additional groups received $35 \mathrm{mg} / \mathrm{kg}$, ip, FLU [a selective serotonin reuptake inhibitor (SSRI)] $24 \mathrm{~h}$ after the last PCPA or saline injection, and $30 \mathrm{~min}$ later were tested in the FST. Involvement of the 5-HT receptor subtypes was also investigated. Animals were pretreated with $0.5 \mathrm{mg} / \mathrm{kg}$, ip, NAN-190 (a 5- $\mathrm{HT}_{1 \mathrm{~A}}$ receptor antagonist), $1 \mathrm{mg} / \mathrm{kg}$, ip, ritanserin (a $5-\mathrm{HT}_{2 \mathrm{~A} / 2 \mathrm{C}}$ receptor antagonist), or $1 \mathrm{mg} / \mathrm{kg}$, ip, ondansetron (a $5-\mathrm{HT}_{3 \mathrm{~A}}$ receptor antagonist), and $30 \mathrm{~min}$ later they received $50 \mathrm{mg} / \mathrm{kg}$, po, H. gordonii or vehicle, and $1 \mathrm{~h}$ later animals were tested in the FST.

To investigate the role of the noradrenergic system on the effects of $H$. gordonii, mice were pretreated with $1 \mathrm{mg} /$ $\mathrm{kg}$, ip, prazosin (an $\alpha 1$-adrenoceptor antagonist) or $1 \mathrm{mg} /$ $\mathrm{kg}$, ip, YOHI (an $\alpha 2$-adrenoceptor antagonist). Additional 
groups of animals received $0.05 \mathrm{mg} / \mathrm{kg}$, ip, $\mathrm{SCH} 23390$ (a dopamine (DA) $D_{1}$ receptor antagonist) or $50 \mathrm{mg} / \mathrm{kg}$, ip, sulpiride [a $D A D_{2}$ receptor antagonist] to evaluate the dopaminergic involvement. Thirty minutes after treatments, mice received orally $50 \mathrm{mg} / \mathrm{kg} \mathrm{H}$. gordonii or vehicle, and $1 \mathrm{~h}$ later, they were tested in the FST.

The doses and administration schedule of the above protocols were chosen on the basis of previous study protocols, and data from the literature confirmed the selectivity and efficacy of the above-mentioned treatments at the concentrations used (14-16). Also, the observer was blinded to the treatments.

\section{Open-field test (OFT)}

To investigate general locomotor activity, mice were treated with $H$. gordonii (25 and $50 \mathrm{mg} / \mathrm{kg}$, po) or vehicle (po) acutely or for 15 consecutive days and were exposed to the OFT $60 \mathrm{~min}$ after the last administration. IMI (10 mg/kg, ip, a classical antidepressant) was used as a positive control.

The OFT involves an apparatus made of an opaquePlexiglas box $(40 \times 30 \times 20 \mathrm{~cm})$ with the floor divided into 9 equal squares. Each animal was gently placed in a corner of the apparatus and its behavior was observed during a 5-min session. A blind observer registered the number of times the animal entered each square (counts per $5 \mathrm{~min}$ ), a count is considered when the animal totally crosses from one square to the next. A change in the number of counts with respect to the control group is considered as an alteration of locomotor activity (17).

\section{Monoamine level determination}

For determination of monoamine levels, control and $H$. gordonii groups (25 and $50 \mathrm{mg} / \mathrm{kg}$ ) were treated acutely or for 15 consecutive days ( $p o$ ) and killed $1 \mathrm{~h}$ after the last treatment. The brain striatum of the mice was dissected on ice for the preparation of a $10 \%$ homogenate $(10 \% \mathrm{w} /$ v) that was sonicated in $0.1 \mathrm{M} \mathrm{HClO}_{4}$, for $30 \mathrm{~s}$ and centrifuged at $20,375 \mathrm{~g}$, for $15 \mathrm{~min}$, at $4^{\circ} \mathrm{C}$. Supernatants were removed and filtered through a membrane (Millipore, Brazil, $0.2 \mathrm{~L}$ ). A $20-\mu \mathrm{L}$ sample of the supernatant was then analyzed by HPLC (Shimadzu, Japan). Concentrations of norepinephrine (NE), DA, and serotonin (5-hydroxytryptamine or 5-HT), and their metabolites, 4-hydroxy-3-methoxy-phenylacetic acid (DOPAC), homovanilic acid (HVA), and 5-hydroxyindoleacetic acid (5HIAA), were detected. Additionally, DA turnover is reported as the ratio of DOPAC to DA (intracellular DA turnover) or HVA to DA (extracellular DA turnover), while $5-\mathrm{HT}$ turnover is reported as the ratio of $5-\mathrm{HIAA}$ to $5-\mathrm{HT}$.

\section{Statistical analysis}

The results are reported as means $\pm S E$. Data were analyzed by one-way ANOVA followed by the Newman Keuls post hoc test. Values were considered to be statistically significant when $\mathrm{P}<0.05$ compared to the control.

\section{Results}

\section{Effect of $\boldsymbol{H}$. gordonii on immobility time in the FST}

Figure $1 \mathrm{~A}$ revealed that the immobility time of animals in the FST was reduced in a significant manner after acute administration of $\mathrm{H}$. gordonii at doses of $25 \mathrm{mg} / \mathrm{kg}$ and $50 \mathrm{mg} / \mathrm{kg}$ ( $\mathrm{H} 25$ and H50) compared to control (df: 28; F: $13.49, \mathrm{P}<0.001)$. IMI-10 (10 mg/kg, ip) was used as the positive control and, as expected, induced similar alterations (df: 28; F: 13.49), $\mathrm{P}<0.001)$. Figure 1B shows that animals treated for 15 consecutive days at doses of 25 mg/kg (df: 28; F: 5.36, P<0.05) and 50 mg/kg (df: 28; $\mathrm{F}: 5.36, \mathrm{P}<0.01$ ) also reduced immobility time compared to the control group. IMI-10 was once again effective as the positive control (df: 28; F: 5.36, $\mathrm{P}<0.01$ ).

\section{Effect of $\boldsymbol{H}$. gordonii on locomotion in the OFT}

Figure 2A shows the results of acute treatment with $H$. gordonii in the OFT. Animals treated with the extract did not alter their locomotor activity when either dose was used compared to the control, and gave results similar to the antidepressant IMI (df: 27; F: 2.74). In Figure 2B, animals treated for 15 consecutive days presented significant reduction of locomotor activity, and IMI did not change this parameter (df: 29; $F: 15.32, P<0.001$ ).

Involvement of the serotonergic, noradrenergic, and dopaminergic systems on the action of $\boldsymbol{H}$. gordonii in the FST

The results presented in Figure $3 \mathrm{~A}$ show that pretreatment of mice with the inhibitor of 5-HT synthesis PCPA $(100 \mathrm{mg} / \mathrm{kg}$, ip, once per day for 4 consecutive days) was able to block the effects of $H$. gordonii $(\mathrm{H} 50)$ in the FST (df: 99; F: 9.88, P<0.05). In a similar way, NAN$190\left(5-\mathrm{HT}_{1 \mathrm{~A}}\right.$ antagonist, $\left.0.5 \mathrm{mg} / \mathrm{kg}, i p\right)$, ritanserin (Ritan; $5-\mathrm{HT}_{2 \mathrm{~A} / 2 \mathrm{C}}$ antagonist, $\left.1 \mathrm{mg} / \mathrm{kg}, i p\right)$, and ondansetron (Onda; $5-\mathrm{HT}_{3 \mathrm{~A}}$ antagonist, $1 \mathrm{mg} / \mathrm{kg}$, ip) blocked the effects of $H$. gordonii (H50) (df: 99; F: 9.88, P<0.05). As expected, PCPA was able to reverse the antidepressantlike effects of FLU (35 mg/kg, ip) (df: 99; F: 9.88, $\mathrm{P}<0.05)$.

Figure 3B demonstrates that pretreatment of mice with both the $\alpha 1$-adrenoceptor antagonist PZS-1 (mg/kg, ip) (df: 47; $\mathrm{F}: 7.87, \mathrm{P}<0.05$ ) and the $\alpha 2$-adrenoceptor antagonist $\mathrm{YOHI}-1$ (mg/kg, ip) (df: 47; F: $7.87 \mathrm{P}<0.05$ ) was able to reverse the antidepressant-like effect of $H$. gordonii $(50 \mathrm{mg} / \mathrm{kg}, \mathrm{po}$ ) in the FST.

The involvement of the dopaminergic system on the action of $H$. gordonii in the FST is shown in Figure 3C. Results show that the anti-immobility effect of $H$. gordonii (50 mg/kg, po) was significantly prevented by the pretreatment of mice with $\mathrm{SCH} 23390(0.5 \mathrm{mg} / \mathrm{kg}$, ip), a dopamine $D_{1}$ receptor antagonist (df: $\left.47 ; F: 4.5, P<0.05\right)$, 

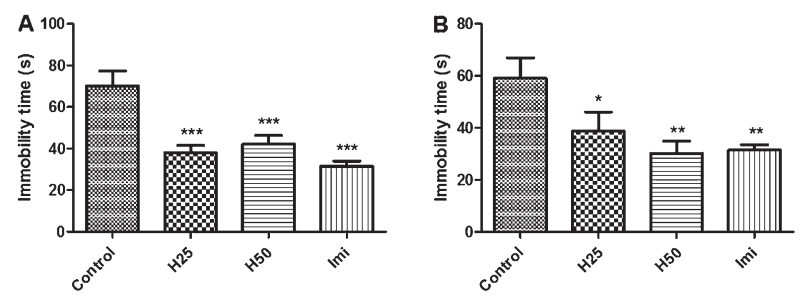

Figure 1. Immobility time in the forced swimming test of mice that received vehicle (control), Hoodia gordonii $[25 \mathrm{mg} / \mathrm{kg}(\mathrm{H} 25)$ and $50 \mathrm{mg} / \mathrm{kg}$ (H50), po] and imipramine (Imi, $10 \mathrm{mg} / \mathrm{kg}$, ip). Animals received $H$. gordonii acutely $(A)$ and for 15 consecutive days $(B)$. Results are reported as means $\pm S E$. ${ }^{*} \mathrm{P}<0.05,{ }^{*} \mathrm{P}<0.01$, ${ }^{* * *} \mathrm{P}<0.001$, compared to control (ANOVA and StudentNewman-Keuls post hoc test).

and sulpiride (50 $\mathrm{mg} / \mathrm{kg}$, ip), a DA $\mathrm{D}_{2}$ receptor antagonist (df: $47 ; \mathrm{F}: 4.5, \mathrm{P}<0.05$ ).

\section{Effect of acute and chronic administration of $H$. gordonii on levels of brain monoamines and metabolites}

Table 1 shows that animals treated with both doses of $H$. gordonii had increased serotonin levels in brain striatum, after acute (df: 20; F: 5.79, $\mathrm{P}<0.05)$ and chronic (df: 21; $\mathrm{F}: 4.30, \mathrm{P}<0.05)$ treatments, compared to the respective control groups. On the other hand, only chronic administration of $H$. gordonii at $50 \mathrm{mg} / \mathrm{kg}$ induced a significant increase in the levels of NE (df: 20; F: 5.64, $P<0.01$ ) and DA (df: 23; F: 3.74, $P<0.05$ ).

Acute and chronic treatments with $H$. gordonii did not induce a significant change in 5-HT turnover (5-HIAA/5$\mathrm{HT}$ ) or intracellular (DOPAC/DA) and extracellular (HVA/ DA) DA turnover, compared to the respective control groups (data not shown).

\section{Discussion}

In this study, we showed that $H$. gordonii extract at doses of 25 and $50 \mathrm{mg} / \mathrm{kg}$, administered acutely and for 15 consecutive days by oral gavage, induced a significant antidepressant-like effect on mice tested in the FST.

The FST remains one of the most common animal models used for screening potential antidepressant agents $(18,19)$. This test induces a state of immobility in animals facing an inescapable situation (in a swim tank). Such immobility behavior has been hypothesized to reflect behavioral despair, which in turn may reflect depressive disorders in humans. Therefore, the antidepressant-like activity of a compound is expressed by a decrease in the immobility of animals submitted to forced swimming. This behavioral change is sensitive to major classes of antidepressant drugs even when administered acutely, including monoamine oxidase inhibitors, tricyclics, selective 5-HT reuptake inhibitors, and atypicals $(9,18,20)$. Thus, our results suggested an antidepressant-like profile
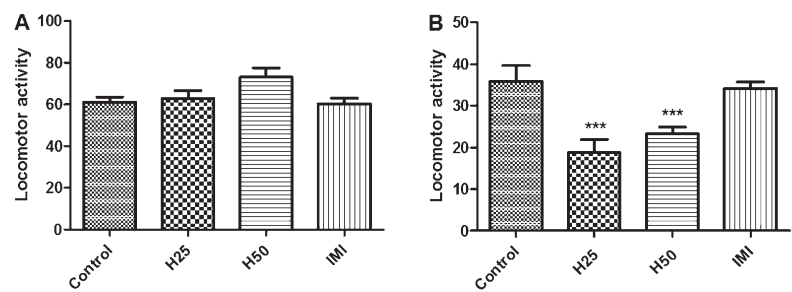

Figure 2. Locomotor activity in the open field test of mice that received saline vehicle (control), Hoodia gordonii $[25 \mathrm{mg} / \mathrm{kg}$ (H25) and $50 \mathrm{mg} / \mathrm{kg}(\mathrm{H} 50), p o]$ and imipramine (IMI, $10 \mathrm{mg} / \mathrm{kg}$, ip). Animals received $H$. gordonii acutely $(A)$ and for 15 consecutive days $(B)$. Results are reported as means \pm SE. ${ }^{* * *} \mathrm{P}<0.001$, compared to control (ANOVA and StudentNewman-Keuls post hoc test).

from $H$. gordonii, also shown by known antidepressant drugs in clinical use, such as FLU, IMI, and others $(9,20,21)$.

Previous studies have shown that CNS stimulant drugs, such as cocaine or amphetamines, are able to decrease immobility in the FST. However, in contrast to antidepressants, stimulant drugs cause marked motor stimulation in tests that evaluate the general activity of animals. As such, this behavior profile is consistent with a false positive effect in the FST model and is often distinguished from the antidepressant-like reduction in immobility by assessing locomotor activity in the OFT $(9,21)$. Thus, to investigate the possibility that $H$. gordonii reduced immobility by a stimulant action, mice were assessed for the ability to increase motor activity in the OFT. This experiment is a common measure of exploratory behavior and general activity in both mice and rats, and therefore it has been frequently used as a mechanism to assess sedative, toxic, or stimulant effects of compounds (22).

Our findings showed that, similar to IMI (10 mg/kg), acute administration of $H$. gordonii at both doses tested (25 and $50 \mathrm{mg} / \mathrm{kg}$ ) did not produce significant changes in locomotion of the animals in the open-field arena. However, there was a tendency toward an increase in locomotion at a higher dose $(50 \mathrm{mg} / \mathrm{kg})$. These results indicated that $H$. gordonii exerted a probable antidepressant-like effect in the FST at relatively low doses. Thus, further investigation is required to investigate a possible increase in ambulation using higher doses of $H$. gordonii. Similar behavioral changes can be observed for instance from bupropion, an effective DA reuptake inhibitor antidepressant used in clinical practice, which induces locomotion in animals only at high doses (23).

For the chronic treatment, mice treated with $H$. gordonii at both doses, for 15 days consecutively, exhibited decreased locomotor activity in the OFT, whereas $10 \mathrm{mg} / \mathrm{kg} \mathrm{IMI}$ was not able to change this parameter. Previous studies have demonstrated a similar decrease in locomotor activity from different antidepressants in the OFT, including acute and chronic IMI at doses 


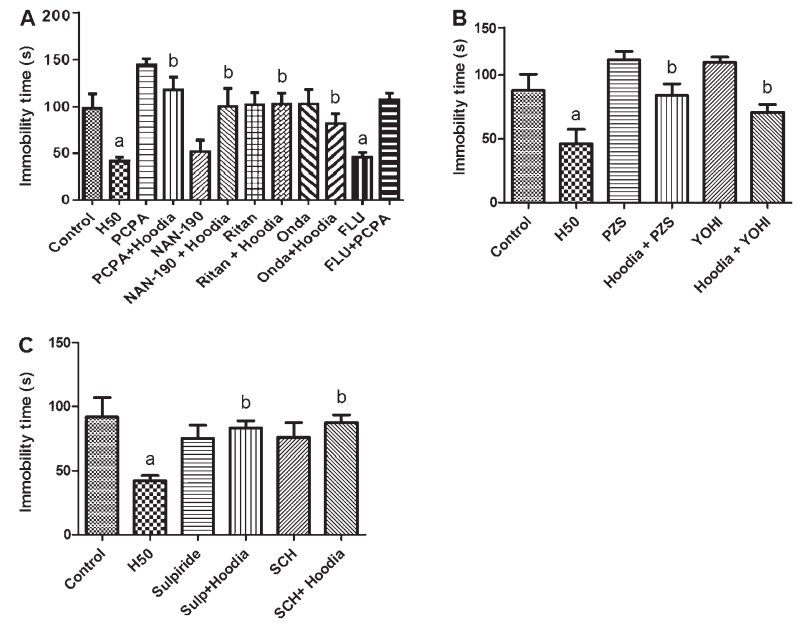

Figure 3. Effects of Hoodia gordonii in the forced swimming test on serotonergic, noradrenergic and dopaminergic systems. A, Pretreatment of animals with $p$-chlorophenylalanine methyl ester (PCPA, $100 \mathrm{mg} / \mathrm{kg}$, ip), ritanserin (Ritan, $1 \mathrm{mg} / \mathrm{kg}, i p$ ), ondansetron (Onda, $1 \mathrm{mg} / \mathrm{kg}$, ip) or vehicle on the effects of $H$. gordonii $(\mathrm{H} 50,50 \mathrm{mg} / \mathrm{kg}, p o$ ). Fluoxetine (Flu, $35 \mathrm{mg} / \mathrm{kg}$, ip) was used as positive control. $B$, Pretreatment of animals with prazosin (PZS, $1 \mathrm{mg} / \mathrm{kg}$, ip) or yohimbine (YOHI, $1 \mathrm{mg} / \mathrm{kg}, i p)$, and $C$, with sulpiride $(50 \mathrm{mg} / \mathrm{kg})$ and SCH $23390(0.05 \mathrm{mg} / \mathrm{kg})$ or vehicle on the effects of $H$. gordonii $(50 \mathrm{mg} / \mathrm{kg}, p o)$. Results are reported as means $\pm \mathrm{SE}$. ${ }^{\mathrm{a}} \mathrm{P}<0.05$, compared to control; ${ }^{\mathrm{b}} \mathrm{P}<0.05$ compared to H. gordonii (ANOVA and Student-Newman-Keuls post hoc test).

as high as 20 or $30 \mathrm{mg} / \mathrm{kg}(21,24)$. Despite the decrease in locomotor activity in the open field, immobility behavior was decreased in the FST, suggesting that such effects from $H$. gordonii treatments were not due to an increase in locomotor activity of the mice. Taken together, our results in the FST and OFT suggest that $H$. gordonii at relatively low doses may act as an antidepressant-like agent.

The monoamine hypothesis of depression predicts that the underlying pathophysiological basis of depression is, at least in part, a depletion in the levels of $5-\mathrm{HT}, \mathrm{NE}$, and/or DA in the CNS. This hypothesis appears to be supported by the mechanism of action of antidepressant drugs, which elevate the levels of these neurotransmitters in the brain. Because the FST also provides a useful model for investigating neurobiological mechanisms underlying antidepressant-like responses (25), the involvement of serotonergic, noradrenergic, and dopaminergic systems on the effects of $H$. gordonii was also investigated using this test. With this aim, we investigated the effects of several pharmacological antagonists/modulators of these systems on the anti-immobility action of H. gordonii in mice.

Most antidepressant drugs in clinical use promote an increase in 5-HT availability by directly inhibiting serotonin reuptake, affecting serotonin turnover in the brain, and also interacting with $5-\mathrm{HT}_{1 \mathrm{~A}}, 5-\mathrm{HT}_{2}$, and $5-\mathrm{HT}_{3 \mathrm{~A}}$ receptors $(26,27)$. In this sense, studies show that PCPA (an inhibitor of tryptophan hydroxylase) administrated to mice or rats for 4 consecutive days is able to deplete the endogenous stores of 5 -HT (by about $60 \%$ ) and prevent the antidepressant-like effect of 5 -HT reuptake inhibitors (SSRIs) like FLU in the FST (28), consistent with the hypothesis that SSRI compounds elicit their acute behavioral effects by increasing extracellular 5- $\mathrm{HT}$. In the present study, the reduction of brain 5-HT by pretreatment of mice with PCPA prevented the antidepressant-like effect of $H$. gordonii, suggesting that the mechanism underlying its effect is possibly dependent on an increase in 5-HT levels in the synaptic cleft. Participation of the serotonergic system is reinforced by demonstrating that the effects of $H$. gordonii

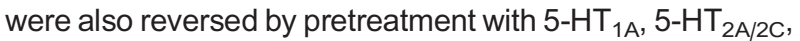
and $5-\mathrm{HT}_{3 \mathrm{~A}}$ receptor antagonists, suggesting a probable involvement of these receptors in its antidepressant-like activity.

In parallel with the serotonergic system, the noradrenergic system is also strongly implicated in the pathophysiology of depression (29). At least in part, depression

Table 1. Determination of levels of monoamines and metabolites in striatum of mice treated with Hoodia gordonii, using high performance liquid chromatography (HPLC).

\begin{tabular}{|c|c|c|c|c|c|c|}
\hline \multirow{2}{*}{$\begin{array}{l}\text { Monoamines and } \\
\text { metabolites }\end{array}$} & \multicolumn{3}{|c|}{ Acute treatment } & \multicolumn{3}{|c|}{ Chronic treatment } \\
\hline & Control & $\mathrm{H} 25$ & $\mathrm{H} 50$ & Control & $\mathrm{H} 25$ & $\mathrm{H} 50$ \\
\hline NE & $2.59 \pm 0.48$ & $4.46 \pm 0.43$ & $3.38 \pm 0.73$ & $2.80 \pm 1.10$ & $2.41 \pm 0.98$ & $7.67 \pm 0.86^{* *}$ \\
\hline DA & $5.21 \pm 0.77$ & $4.27 \pm 0.99$ & $5.44 \pm 1.09$ & $4.66 \pm 0.91$ & $5.46 \pm 0.88$ & $7.61 \pm 0.50^{*}$ \\
\hline HVA & $5.53 \pm 1.08$ & $3.69 \pm 0.65$ & $2.59 \pm 0.24$ & $1.88 \pm 0.30$ & $2.22 \pm 0.67$ & $3.32 \pm 0.54$ \\
\hline DOPAC & $3.76 \pm 0.90$ & $2.50 \pm 0.21$ & $3.17 \pm 0.34$ & $3.38 \pm 0.41$ & $3.48 \pm 0.48$ & $3.92 \pm 0.89$ \\
\hline $5-\mathrm{HT}$ & $2.60 \pm 0.87$ & $6.83 \pm 1.12^{*}$ & $5.76 \pm 0.63^{*}$ & $1.78 \pm 0.20$ & $5.17 \pm 1.11^{*}$ & $4.43 \pm 0.89^{*}$ \\
\hline 5-HIAA & $5.05 \pm 1.01$ & $5.07 \pm 1.37$ & $3.62 \pm 0.91$ & $4.02 \pm 1.24$ & $3.58 \pm 1.15$ & $3.54 \pm 1.47$ \\
\hline
\end{tabular}

Animals received acute and chronic (15-days) administration of $H$. gordonii (25 and $50 \mathrm{mg} / \mathrm{kg}$, po, $\mathrm{H} 25$ and H50, respectively) or vehicle. Data are reported as means \pm SE in $n m o l / g$ tissue $(n=7-8)$. NE: noradrenaline; DA: dopamine; DOPAC: 3,4dihydroxyphenylacetic acid; 5-HT: serotonin; 5-HIAA: 5-hydroxy-3-indoleacetic acid; HVA: homovanilic acid. ${ }^{*} \mathrm{P}<0.05$; ${ }^{* *} \mathrm{P}<0.01$, compared to control (one-way ANOVA and Newman Keuls post hoc test). 
seems to also be associated with a hypofunction of the noradrenergic system, so that some antidepressants act by increasing the synaptic availability of NE (26). In this context, the $\alpha 1$ - and $\alpha 2$-adrenoceptors have been shown to underlie some of the antidepressant-like responses of drugs in behavioral models of depression $(29,30)$. Our results showed that pretreatment of mice with both prazosin and $\mathrm{YOHI}(\alpha 1$ - and $\alpha 2$-adrenoceptor antagonists, respectively) was able to reverse the antidepressant-like effect of $H$. gordonii. These findings indicated that the effect of $H$. gordonii in the FST involved, at least in part, an interaction with $\alpha 1$ - and $\alpha 2$-adrenoceptors, suggesting the participation of the noradrenergic system in the antidepressant-like action induced by this plant extract

Studies show that the dopaminergic system, in part, may also be implicated in the regulation of mood (31). Currently, there is evidence from several reports regarding the efficacy of antidepressants related to the potentiation of dopaminergic neurotransmission in the treatment of depression $(31,32)$. Our results showed that the dopaminergic system was also involved in the antiimmobility effect of $H$. gordonii through an interaction with both $D A D_{1}$ and $D_{2}$ receptors, because pretreatment of the mice with $\mathrm{SCH} 23390$ (a DA $D_{1}$ receptor antagonist) or sulpiride (a $D A D_{2}$ receptor antagonist) prevented the antiimmobility effect evoked by $H$. gordonii. These results are in accordance with previous studies, which have reported that the anti-immobility effect of tricyclic antidepressants such as IMI (and others) was related, at least in part, to $D_{2}$ receptors (32). Additionally, although the role of DA $D_{1}$ receptors in the action mechanism of antidepressants is still controversial, several studies have also shown their involvement in depression and on the action mechanism of antidepressants (33).

Together, behavioral changes evoked by $H$. gordonii in the FST suggested an antidepressant-like effect after acute and repeated administration of the plant extract, which seem to be mediated by an interaction with the serotonergic, noradrenergic, and dopaminergic systems. Thus, in order to corroborate these findings, we additionally quantified monoamine (5-HT, NE, and DA) and metabolite (DOPAC, HVA, and 5-HIAA) levels in brain striatum of mice that received acute and chronic (15 days) treatment with $H$. gordonii (25 and $50 \mathrm{mg} / \mathrm{kg}, \mathrm{po}$ ). Although hippocampus, hypothalamus, and cortex areas have been strongly related to the antidepressant mechanism of several drugs (34), studies show that the striatum is also a relevant brain area involved in the action of these compounds $(35,36)$. For instance, Kreiss and Lucki (35) showed that acute and repeated administration of FLU (an SSRI) elevated the levels of $5-\mathrm{HT}$ in the striatum of rats, while Ichikawa and Meltzer (36) showed that IMI (a tricyclic) significantly increased extracellular DA in the striatum.
Consistent with previous studies that show a strong relationship between the mechanism of antidepressants and changes in striatal monoamine levels, the present neurochemical analysis conducted by HPLC revealed significant increased levels of monoamines in brain striatum of mice treated with $H$. gordonii. Results showed that only $5-\mathrm{HT}$ monoamine was significantly increased after acute administration of $H$. gordonii, at both doses tested, while an increase of all three monoamines (5-HT, $\mathrm{DA}$, and NE) was observed after chronic administration at $50 \mathrm{mg} / \mathrm{kg}$. These results corroborated our hypothesis that the antidepressant-like effect exhibited by $H$. gordonii extract in the FST is, indeed, related to the serotonergic, noradrenergic, and dopaminergic systems.

More specifically, our findings showed that the effects of $H$. gordonii are dependent on increases in 5-HT, NE, and DA levels in the synaptic cleft, mainly after repeated administration at higher doses, suggesting that neuronal adaptive changes may develop following long-term treatment that sustain higher levels of NE and DA than can be achieved following acute administration. In addition, elevated NE levels detected in this study are in accordance with previous reports that associate $H$. gordonii to significant increases in blood pressure and pulse rate (6). However, it must be emphasized that only one discrete brain region was examined in this study and it is quite possible that functional changes occur at other sites.

In summary, the present study provided evidence indicating that acute and chronic (15 days) oral administration of $H$. gordonii extract at doses of 25 and $50 \mathrm{mg} / \mathrm{kg}$ exhibited a probable antidepressant-like effect in mice exposed to the FST. This action was not related to a psychostimulant effect in the OFT. Furthermore, behavioral alterations observed in the FST and OFT seem to be mediated, at least in part, by an interaction with the serotonergic, noradrenergic, and dopaminergic systems, including increases in monoamine (5-HT, NE, and DA) levels in the striatum of mice. Our results raise the perspective for further investigation on behavioral changes and neurochemical mechanisms involved in antidepressant-like effects elicited by $H$. gordonii. However, because the present results were obtained using a dry extract of the plant at a dilution of $20: 1$ and the substances contained in this extract were not used in the vehicle groups, future research is also required to confirm the present effects.

\section{Acknowledgments}

The authors are grateful to CNPq and CAPES for financial support. 


\section{References}

1. Wong ML, Licinio J. Research and treatment approaches to depression. Nat Rev Neurosci 2001; 2: 343-351, doi: 10.1038/ 35072566.

2. Tran PV, Bymaster FP, McNamara RK, Potter WZ. Dual monoamine modulation for improved treatment of major depressive disorder. J Clin Psychopharmacol 2003; 23: 7886, doi: 10.1097/00004714-200302000-00011.

3. Dhingra D, Valecha R. Evidence for involvement of the monoaminergic system in antidepressant-like activity of an ethanol extract of Boerhaavia diffusa and its isolated constituent, punarnavine, in mice. Pharm Biol 2014; 52: 767-774, doi: 10.3109/13880209.2013.870583.

4. Teixeira CP, de Melo CT, de Araujo FL, de Carvalho AM, Silva $\mathrm{MI}$, Barbosa-Filho JM, et al. Antidepressant-like effect of riparin II from Aniba riparia in mice: evidence for the involvement of the monoaminergic system. Fundam Clin Pharmacol 2013; 27: 129-137, doi: 10.1111/j.1472-8206.2011.00973.x.

5. Bhattacharya SK, Bhattacharya A, Sairam K, Ghosal S. Anxiolytic-antidepressant activity of Withania somnifera glycowithanolides: an experimental study. Phytomedicine 2000; 7: 463-469, doi: 10.1016/S0944-7113(00)80030-6.

6. van Heerden FR. Hoodia gordonii: a natural appetite suppressant. J Ethnopharmacol 2008; 119: 434-437, doi: 10.1016/j.jep.2008.08.023.

7. van Heerden FR, Marthinus HR, Maharaj VJ, Vleggaar R, Senabe JV, Gunning PJ. An appetite suppressant from Hoodia species. Phytochemistry 2007; 68: 2545-2553, doi: 10.1016/j.phytochem.2007.05.022.

8. Blom WA, Abrahamse SL, Bradford R, Duchateau GS, Theis W, Orsi A, et al. Effects of 15-d repeated consumption of Hoodia gordonii purified extract on safety, ad libitum energy intake, and body weight in healthy, overweight women: a randomized controlled trial. Am J Clin Nutr 2011; 94: 1171-1181, doi: 10.3945/ajcn.111.020321.

9. Porsolt RD, Bertin A, Jalfre M. Behavioral despair in mice: a primary screening test for antidepressants. Arch Int Pharmacodyn Ther 1977; 229: 327-336.

10. Chen PJ, Hsieh CL, Su KP, Hou YC, Chiang HM, Sheen LY. Rhizomes of Gastrodia elata B(L) possess antidepressantlike effect via monoamine modulation in subchronic animal model. Am J Chin Med 2009; 37: 1113-1124, doi: 10.1142/ S0192415X09007533.

11. Cryan JF, Markou A, Lucki I. Assessing antidepressant activity in rodents: recent developments and future needs. Trends Pharmacol Sci 2002; 23: 238-245, doi: 10.1016/ S0165-6147(02)02017-5.

12. do Amaral JF, Silva MI, de Aquino Neto MR, Moura BA, de Carvalho AM, Vasconcelos PF, et al. Antidepressant-like effect of bis-eugenol in the mice forced swimming test: evidence for the involvement of the monoaminergic system. Fundam Clin Pharmacol 2013; 27: 471-482, doi: 10.1111/ j.1472-8206.2012.01058.x.

13. Einat $\mathrm{H}$, Clenet $\mathrm{F}$, Shaldubina $\mathrm{A}$, Belmaker $\mathrm{RH}$, Bourin $\mathrm{M}$. The antidepressant activity of inositol in the forced swim test involves 5-HT(2) receptors. Behav Brain Res 2001; 118: 7783, doi: 10.1016/S0166-4328(00)00314-4.

14. Machado DG, Kaster MP, Binfare RW, Dias M, Santos AR, Pizzolatti MG, et al. Antidepressant-like effect of the extract from leaves of Schinus molle L. in mice: evidence for the involvement of the monoaminergic system. Prog Neuropsychopharmacol Biol Psychiatry 2007; 31: 421-428, doi: 10.1016/j.pnpbp.2006.11.004.

15. Posser T, Kaster MP, Barauna SC, Rocha JB, Rodrigues $A L$, Leal RB. Antidepressant-like effect of the organoselenium compound ebselen in mice: evidence for the involvement of the monoaminergic system. Eur J Pharmacol 2009; 602: 85-91, doi: 10.1016/j.ejphar.2008.10.055.

16. Melo CT, de Carvalho AM, Moura BA, Teixeira CP, Vasconcelos LF, Feitosa ML, et al. Evidence for the involvement of the serotonergic, noradrenergic, and dopaminergic systems in the antidepressant-like action of riparin III obtained from Aniba riparia (Nees) Mez (Lauraceae) in mice. Fundam Clin Pharmacol 2013; 27: 104-112, doi: 10.1111/ j.1472-8206.2011.00968.x.

17. Archer J. Tests for emotionality in rats and mice: a review. Anim Behav 1973; 21: 205-235, doi: 10.1016/S00033472(73)80065-X.

18. Petit-Demouliere B, Chenu F, Bourin M. Forced swimming test in mice: a review of antidepressant activity. Psychopharmacology 2005; 177: 245-255, doi: 10.1007/s00213004-2048-7.

19. Silva MI, de Aquino Neto MR, Teixeira Neto PF, Moura BA, do Amaral JF, de Sousa DP, et al. Central nervous system activity of acute administration of isopulegol in mice. Pharmacol Biochem Behav 2007; 88: 141-147, doi: 10.1016/j.pbb.2007.07.015.

20. Porsolt RD, Bertin A, Jalfre M. "Behavioural despair" in rats and mice: strain differences and the effects of imipramine. Eur J Pharmacol 1978; 51: 291-294, doi: 10.1016/0014-29 99(78)90414-4.

21. Refaey HEL, Amri HS. Effects of antidepressants on behavioral assessment in adolescent rats. Bahrain Med Bull 2014; 33: 1-12.

22. Walsh RN, Cummins RA. The Open-Field Test: a critical review. Psychol Bull 1976; 83: 482-504, doi: 10.1037/00332909.83.3.482.

23. Nielsen JA, Shannon NJ, Bero L, Moore KE. Effects of acute and chronic bupropion on locomotor activity and dopaminergic neurons. Pharmacol Biochem Behav 1986; 24: 795-799, doi: 10.1016/0091-3057(86)90413-2.

24. Reus GZ, Abelaira HM, dos Santos MA, Carlessi AS, Tomaz DB, Neotti MV, et al. Ketamine and imipramine in the nucleus accumbens regulate histone deacetylation induced by maternal deprivation and are critical for associated behaviors. Behav Brain Res 2013; 256: 451-456, doi: 10.1016/j.bbr.2013.08.041.

25. Cardoso CC, Lobato KR, Binfare RW, Ferreira PK, Rosa $A O$, Santos AR, et al. Evidence for the involvement of the monoaminergic system in the antidepressant-like effect of magnesium. Prog Neuropsychopharmacol Biol Psychiatry 2009; 33: 235-242, doi: 10.1016/j.pnpbp.2008.11.007.

26. Elhwuegi AS. Central monoamines and their role in major depression. Prog Neuropsychopharmacol Biol Psychiatry 2004; 28: 435-451, doi: 10.1016/j.pnpbp.2003.11.018.

27. Stahl SM, Lee-Zimmerman C, Cartwright S, Morrissette DA. Serotonergic drugs for depression and beyond. Curr Drug Targets 2013; 14: 578-585, doi: 10.2174/1389450111314 050007. 
28. O'Leary OF, Bechtholt AJ, Crowley JJ, Hill TE, Page ME, Lucki I. Depletion of serotonin and catecholamines block the acute behavioral response to different classes of antidepressant drugs in the mouse tail suspension test. Psychopharmacology 2007; 192: 357-371, doi: 10.1007/ s00213-007-0728-9.

29. Kitada $\mathrm{Y}$, Miyauchi T, Kanazawa $\mathrm{Y}$, Nakamichi H, Satoh S. Involvement of alpha- and beta 1-adrenergic mechanisms in the immobility-reducing action of desipramine in the forced swimming test. Neuropharmacology 1983; 22: 1055-1060, doi: 10.1016/0028-3908(83)90024-2.

30. Stone EA, Grunewald GL, Lin Y, Ahsan R, Rosengarten H, Kramer HK, et al. Role of epinephrine stimulation of CNS alpha1-adrenoceptors in motor activity in mice. Synapse 2003; 49: 67-76, doi: 10.1002/syn.10212.

31. D'Aquila PS, Collu M, Gessa GL, Serra G. The role of dopamine in the mechanism of action of antidepressant drugs. Eur J Pharmacol 2000; 405: 365-373, doi: 10.1016/ S0014-2999(00)00566-5.

32. Dziedzicka-Wasylewska M, Kolasiewicz W, Rogoz Z, Margas W, Maj J. The role of dopamine D2 receptor in the behavioral effects of imipramine - study with the use of antisense oligonucleotides. J Physiol Pharmacol 2000; 51: 401-409.

33. Yamada J, Sugimoto $Y$, Yamada S. Involvement of dopamine receptors in the anti-immobility effects of dopamine re-uptake inhibitors in the forced swimming test. Eur $\mathrm{J}$ Pharmacol 2004; 504: 207-211, doi: 10.1016/ j.ejphar.2004.09.057.

34. Butterweck V, Bockers T, Korte B, Wittkowski W, Winterhoff $\mathrm{H}$. Long-term effects of St. John's wort and hypericin on monoamine levels in rat hypothalamus and hippocampus. Brain Res 2002; 930: 21-29, doi: 10.1016/S00068993(01)03394-7.

35. Kreiss DS, Lucki I. Effects of acute and repeated administration of antidepressant drugs on extracellular levels of 5hydroxytryptamine measured in vivo. J Pharmacol Exp Ther 1995; 274: 866-876.

36. Ichikawa J, Meltzer HY. Effect of antidepressants on striatal and accumbens extracellular dopamine levels. Eur $J$ Pharmacol 1995; 281: 255-261, doi: 10.1016/00142999(95)00264-L. 